\title{
Regulating Horizontal Diversification
}

by

\author{
David E. M. Sappington*
}

\begin{abstract}
This paper investigates the optimal design of diversification rules for regulated enterprises. Diversification by a regulated firm generates profit in non-core markets that can be shared with core customers. However, a diversified firm may divert its attention and effort to its non-core operations, causing consumer welfare in the core market to decline. When diversification is permitted, lower prices and higher-powered reward structures are generally implemented in the core market. Surprisingly, diversification is not always directed into the non-core markets where the expected contribution of the regulated firm is most pronounced. Furthermore, diversification may be permitted more often as the potential losses from effort diversion increase.

Key Words: $\quad$ Regulation, Diversification.

JEL Classifications: L51, D82.
\end{abstract}

January 2001

* Department of Economics, University of Florida, P.O. Box 117140, Gainesville, FL 32611. Voice: (352) 392-3904; Facsimile: (352) 336-1420; E-mail: sapping@ufl.edu. 


\section{Introduction.}

Regulated firms are often permitted to diversify into new markets. Regulated suppliers of local telephone service (e.g., the Regional Bell Operating Companies (RBOCs)) now provide broadband Internet service in their operating territories, for example. Electricity providers (e.g., Northern States Power and Potomac Electric and Power Company) are also beginning to provide communications

services. ${ }^{1}$ There are instances, however, where regulated firms (e.g., RBOCs) are prohibited from diversifying into unregulated markets (e.g., long distance telephone service).

One reason for prohibiting diversification is to remove any temptation a monopoly supplier of an essential input might have to disadvantage downstream competitors, perhaps by limiting their access to the essential input. The merits of this argument have received considerable attention in the literature. ${ }^{2}$ In contrast, the literature has afforded relatively little attention to the merits of permitting regulated firms to diversify into unregulated markets when these vertical issues are absent. ${ }^{3}$ The purpose of this research is to analyze the optimal design of diversification policy when these vertical considerations do not arise.

Horizontal diversification can provide important benefits for customers of the firm's core regulated service. In particular, some of the profit the firm earns in non-core markets can be taxed

1. Federal Communications Commission (1999, II 137).

2. For some recent analyses of this issue, see Vickers (1995), Weisman (1995), Hinson et al. (1998), Riordan (1998), Sibley and Weisman (1998), Economides (1998, 1999), Lee and Hamilton (1999), Mandy (2000), and Mandy and Sappington (2000).

3. Averch and Johnson (1969) note that a regulated firm may have excessive incentive to diversify in order to expand its rate base. Braeutigam and Panzar (1989), Crew and Crocker (1991), and Weisman (1993) analyze the incentives for diversification and cost shifting that arise under common regulatory rules. The present analysis differs from its predecessors by deriving the optimal diversification policy when stochastic cost shifting and cost padding are possible. Additional related literature is discussed shortly. 
(explicitly or implicitly) and delivered to core customers. However, diversification may also harm core customers if the prospect of significant profit in non-core markets induces the regulated firm to divert its creative energies from its core market to non-core markets. This is the essential tradeoff that complicates the design of diversification policy in the present analysis.

A simple model is developed here to analyze this element of optimal diversification policy. In the model, diversification would be advantageous for core customers if the aforementioned effort diversion problem were not present and if the regulator were well informed about operations in noncore markets, and so could distinguish between necessary and unnecessary expenditures by the regulated firm in these markets. As shown below, if the regulator were well informed in this respect and so could detect and eliminate cost padding, he could prevent effort diversion, and so would always authorize diversification. The regulator would also always authorize diversification if he could monitor perfectly the firm's allocation of cost-reducing effort across markets, even if he could not prevent cost padding. But the combination of effort diversion and cost padding problems can cause the regulator to prohibit diversification.

Not surprisingly, the regulator is more likely to prohibit diversification when the regulator's knowledge of non-core markets is limited, when the incremental surplus that the regulated firm is certain to secure in non-core markets is small, and when the potential cost variation in the core market is large (so the gains from reducing costs in the core market are large). Perhaps more surprisingly, the regulator may optimally prohibit diversification into non-core markets where the regulated firm's ability to generate incremental expected surplus is especially pronounced while 
permitting diversification into markets where the firm's corresponding ability is more limited. ${ }^{4}$ In addition, the regulator may authorize diversification into a given non-core market when the impact of the firm's cost-reducing effort in the core market (and thus the potential loss from effort diversion) is substantial, but preclude diversification when the impact is more limited. ${ }^{5}$ Whenever the regulator authorizes diversification, he admits profit in the core market that increases as realized operating costs decline. Doing so limits the incentive of the regulated firm to divert effort from its core operations to its non-core operations.

These findings are developed as follows. The simple model analyzed here is described in section 2. Some benchmark outcomes are discussed in section 3 . Section 4 characterizes the optimal reward structure under three distinct policies: (1) when diversification is precluded; (2) when diversification is authorized and the firm employs its cost-reducing effort in the non-core market; and (3) when diversification is authorized and the firm is induced to focus its effort in the core market. Section 5 provides conditions under which each of these policies is optimal. The primary conclusions and policy implications of this research are summarized in section 6. Proofs of all formal conclusions are relegated to the Appendix.

Before proceeding, the present analysis is contrasted with the most closely related analyses in the literature. Brennan (1990) and Brennan and Palmer (1994) determine how scope economies and potential cost shifting affect the merits of diversification in a setting where the regulated firm must

4. The reason is that the same factors that render the firm more productive in non-core markets can also make it more difficult to deter effort diversion by the diversified firm.

5. As the impact of the firm's cost-reducing effort increases in the core market, the costs of motivating the diversified firm to focus its effort in the core market can decline, which can increase the expected returns from diversification. 
be guaranteed non-negative profit on its core operations. Cost shifting occurs when the diversified firm counts costs actually incurred in serving non-core customers as costs of serving core customers, and thereby reduces measured profit from core operations. In the present analysis, the regulated firm need only be guaranteed non-negative profit on its combined operations, so cost shifting per se is not advantageous for the firm. ${ }^{6}$ However, the effort diversion analyzed here might be viewed as a form of stochastic cost shifting, in that the expected cost of serving core customers is increased when the regulated firm devotes cost-reducing effort to non-core markets. In addition to analyzing stochastic cost shifting (and, effectively, stochastic scope economies), this research extends Brennan's (1990) and Brennan and Palmer's (1994) important research by deriving the optimal regulatory policy toward diversification, explicitly examining how to best limit stochastic cost shifting, and determining when it is optimal to do so. ${ }^{7}$

The present analysis also extends Braeutigam's (1993) interesting analysis of diversification policy. Braeutigam proposes and documents the merits of a regulatory rule that limits the profit the

6. This same approach is adopted in Braeutigam (1993). In practice, a regulator is not always free to employ profits earned in unregulated markets to keep prices low in regulated markets (Sidak and Spulber, 1998, pp. 313-316). But regulators can balance earnings across regulated services. The main qualitative conclusions drawn below continue to hold when prices in non-core markets are regulated. The primary change in this setting is that the price set in the non-core market serves as an extra policy instrument for the regulator. But even with this additional instrument at his disposal, the regulator continues to authorize core profit that increases as core operating costs decline. He may also prohibit diversification into markets where the regulated firm's ability to generate incremental expected surplus is especially pronounced, and he may authorize diversification even when the potential loss from effort diversion is substantial.

7. Brennan's (1990) and Brennan and Palmer's (1994) models include elements that are not analyzed here. These elements include elastic demand, intentional technological distortions by the regulated firm, and different forms of competition in non-core markets. Crew and Crocker (1991) also demonstrate how a diversified firm will choose its production technology strategically in response to the diversification policy and cost allocation rules under which it operates. See Baseman (1981) for a related analysis. 
firm is permitted to earn in all markets to a fraction of the surplus it generates for core customers. The approach taken here differs from Braeutigam's approach in three important respects. First, and most importantly, the optimal diversification and associated pricing policy is derived here. Thus, the present analysis identifies the manner in which realized surplus is optimally shared between the regulated firm and its core customers. ${ }^{8}$ Second, the potential problems associated with effort diversion are analyzed here. ${ }^{9}$ Third, the present analysis admits the realistic possibility that the firm might derive personal gains (e.g., managerial perquisites) from its cost padding expenditures. ${ }^{10}$

\section{The Model.}

There is a single regulated firm that may operate in both a core market and a non-core market. ${ }^{11}$ The firm always satisfies all customer demand in the core market. For simplicity and to reflect the essential nature of the core service, consumer demand in the core market is assumed to be perfectly inelastic at output level $\bar{Q}$ up to a reserve price, $\bar{p}$. Production costs in the core market are stochastic and, for simplicity, binary. The firm's marginal (and average) cost of production in the core market

8. The optimal policy is identified here in a setting that is simpler in some respects than the setting analyzed by Braeutigam (1993). In particular, Braeutigam admits an arbitrary number of core and non-core products, elastic demand functions, and non-linear cost functions.

9. See Holmstrom and Milgrom (1991) for an elegant discussion and analysis of the effort diversion problem in a different setting. Brennan (1989) provides a useful general analysis of when exclusive dealing restrictions and limits on outside activities can mitigate conflicts of interest, and thereby enhance the performance of vertical relationships.

10. The different approaches lead to different qualitative conclusions. For example, Braeutigam's surplus-sharing rule induces the regulated firm to diversify into competitive markets if and only if the firm's production technology exhibits economies of scope. Under the optimal policy derived here, the firm may be prohibited from diversifying into non-core markets even though it is the least-cost supplier in those markets.

11. A single non-core market is considered for expositional simplicity. Some implications of the analysis for settings with multiple non-core markets are mentioned as the discussion proceeds. 
is $c \in\left\{c_{L}, c_{H}\right\}$, where $0<c_{L}<c_{H} \cdot{ }^{12}$ The firm realizes low $\cos t\left(c_{L}\right)$ with probability $\varphi \in(0,1)$ and high cost $\left(c_{H}\right)$ with probability $1-\varphi$.

By devoting effort to its core operations, the firm can reduce its expected operating cost in the core market. Formally, when it devotes its effort to the core market, the firm increases the probability of low cost $\left(c_{L}\right)$ from $\varphi_{0}$ to $\varphi_{0}+\Delta^{c}$, where $\Delta^{c} \in\left(0,1-\varphi_{0}\right)$. The regulator knows the values of $\varphi_{0}$ and $\Delta^{c}$ (and all other relevant parameters), but cannot observe the firm's effort supply. Despite this fact, the regulator does not face a traditional moral hazard problem because effort is assumed to impose no direct costs on the firm. This may be the case, for example, either when managers in the firm enjoy their work, or when they work diligently without the promise of immediate financial reward, perhaps because superior current performance enhances future employment prospects.

Although the firm is not averse to delivering cost-reducing effort, it may find it more profitable to devote its limited, indivisible supply of effort to its non-core operations when such operations are authorized. The non-core market is characterized by competition among firms that produce a homogenous product with constant returns to scale. Absent participation by the regulated firm, intense competition in the non-core market drives the market price to the level of marginal cost of the least-cost supplier, $\bar{c}^{n}$. For simplicity, consumer demand in the non-core market is assumed to be perfectly inelastic (up to a reserve price, $\bar{p}^{n}$ ) at output level $\bar{Q}^{n}$.

If the regulated firm is permitted to diversify and thus to operate in the non-core market, its marginal cost of production is either low $\left(c_{L}^{n}\right)$ or high $\left(c_{H}^{n}\right)$. To focus on the case where diversification always has the potential to increase welfare, the regulated firm is assumed to be the

12. Fixed costs of production are ignored for expositional simplicity. The central qualitative conclusions drawn below remain unchanged if fixed costs are present. 
most efficient producer in the non-core market, i.e., $c_{H}^{n} \leq \bar{c}^{n} \cdot{ }^{13}$ The regulated firm can reduce its expected cost in the non-core market by devoting its cost-reducing effort to that market. Formally, the regulated firm can increase the probability of low non-core costs $\left(c_{L}^{n}\right)$ from $\varphi_{0}^{n} \in(0,1)$ to $\varphi_{0}^{n}+\Delta^{n}$ (where $\left.\Delta^{n} \in\left(0,1-\varphi_{0}^{n}\right)\right)$ by devoting its (unobservable) cost-reducing effort to its non-core operations. When it devotes this effort to its non-core operations rather than its core operations, the regulated firm is said to engage in effort diversion.

As shown below, the regulator could preclude effort diversion costlessly if he could always observe the firm's realized production costs in the non-core market. In practice, though, perfect measurement of costs can be problematic when the regulator is not intimately familiar with operations in the non-core market. To capture the regulator's inability to distinguish between essential and inessential production costs in the non-core market, the firm is assumed to be able to undertake unnecessary expenditures that inflate low realized costs $\left(c_{L}^{n}\right)$ to the level of high costs $\left(c_{H}^{n}\right)$. These unnecessary expenditures may provide some direct value to the firm (in the form of managerial perquisites, for example). $\delta \in[0,1]$ will denote the portion of unnecessary expenditures that are truly wasteful, and provide no direct value to the firm. The firm values the remaining portion $(1-\delta)$ of unnecessary expenditures exactly as it values profit. Thus, $\delta$ might be interpreted as the unit cost to the firm of inflating its marginal cost of production in the non-core market. ${ }^{14}$ Lower values of $\delta$ might arise in settings where the regulator is less familiar with operations in the non-core

13. The basic tradeoffs identified below persist if the regulated firm is not always the least-cost supplier in the non-core market. In this case, of course, the regulator is less likely to authorize diversification, ceteris paribus.

14. In practice, a firm might face an increasing cost of inflating its marginal cost of production. More tractable and more complete characterizations of the regulator's optimal policy are admitted by abstracting from this nonlinearity. 
market, and thus is less capable of distinguishing between necessary and unnecessary expenditures.

The regulator has two instruments at his disposal: the authorized level of diversification and prices in the core market. The authorized level of diversification is the maximum output, $Q^{n}$, the regulated firm is permitted to produce in the non-core market. The price in the non-core market is not regulated. Competition drives this price to $\bar{c}^{n}$, whatever the authorized level of diversification. ${ }^{15}$ The unit price that the regulator sets in the core market can vary with the regulated firm's observed operating costs in both the core and the non-core markets. (Recall that the firm can pad its costs in the non-core market, i.e., inflate them from $c_{L}^{n}$ to $c_{H}^{n}$. The firm cannot similarly pad its costs in the core market because the regulator is well informed about necessary expenditures in this market. ${ }^{16} p_{i j}$ will denote the unit price set in the core market when the regulated firm's observed marginal costs are $c_{i}$ and in the core market and $c_{j}^{n}$ in the non-core market.

The regulated firm cannot be forced to operate against its will. Therefore, the regulator must set prices and authorized diversification levels to ensure non-negative profit for the firm. The firm will tolerate negative profit from its core operations if this loss is offset by positive profit from non-core operations. Therefore, the regulator may be able to secure greater surplus for consumers in the core market by allowing the regulated firm to diversify into the non-core market. The regulator seeks to maximize expected consumers' surplus in the core market. ${ }^{17}$

15. The profit-maximizing price for the regulated firm in the non-core market is $\bar{c}^{n}$, the marginal cost of the next most efficient producer in that market.

16. The key qualitative conclusions drawn below would persist if the regulated firm could undertake cost padding in the core market, provide such padding is more costly for the firm in the core market than in the non-core market.

17. The regulator might also value consumers' surplus in the non-core market. However, this surplus is unaltered by regulatory policy because the price in the non-core market is always $\bar{c}^{n}$. 
The interaction between the regulator and the regulated firm proceeds as follows. The regulator first specifies the level of authorized diversification $\left(Q^{n}\right)$ and the prices $\left(p_{i j}\right)$ that will be set in the core market for all possible pairs of observed cost realizations $\left(c_{i}, c_{j}{ }^{n}\right)$. The firm then decides where it will allocate its (unobservable) cost-reducing effort. Marginal production costs are realized next. If it operates in the non-core market and realizes low costs $\left(c_{L}^{n}\right)$ there, the firm can pad its costs (at personal marginal cost $\delta$ ) so that the regulator perceives non-core production costs to be high $\left(c_{H}^{n}\right)$. After observing the firm's operating costs, the regulator implements the promised price in the core market, and customers are served at the prevailing prices in both markets. This interaction is not repeated.

When he chooses to deter effort diversion in this setting, the regulator's problem, denoted $[E C]$, is the following. ${ }^{18}$

$\underset{p_{i j}, Q^{n}}{\operatorname{Maximize}} \bar{Q}\left[\bar{p}-\varphi \varphi^{n} p_{L L}-[1-\varphi] \varphi^{n} p_{H L}-\varphi\left[1-\varphi^{n}\right] p_{L H}-[1-\varphi]\left[1-\varphi^{n}\right] p_{H H}\right]$

subject to:

$$
\begin{aligned}
& {\left[p_{i j}-c_{i}\right] \bar{Q}+Q^{n}\left[\bar{c}^{n}-c_{j}^{n}\right] \geq 0 \text { for all } i, j=L, H} \\
& {\left[p_{i L}-c_{i}\right] \bar{Q}+\left[\bar{c}^{n}-c_{L}^{n}\right] Q^{n} \geq\left[p_{i H}-c_{i}\right] \bar{Q}+\left[\bar{c}^{n}-c_{H}^{n}\right] Q^{n}+[1-\delta]\left[c_{H}^{n}-c_{L}^{n}\right] Q^{n}} \\
& \text { whenever } Q^{n}>0, \text { for } i=L, H ; \\
& \varphi^{n}\left\{\bar{Q}\left[\varphi\left[p_{L L}-c_{L}\right]+[1-\varphi]\left[p_{H L}-c_{H}\right]\right]+\left[\bar{c}^{n}-c_{L}^{n}\right] Q^{n}\right\}
\end{aligned}
$$

The qualitative conclusions drawn below would also not change if the regulator sought to maximize a weighted average of consumers' surplus and profit, where a larger weight is placed on consumers' surplus.

18. The letters $E C$ denote effort in the core market. 


$$
\begin{aligned}
& +\left[1-\varphi^{n}\right]\left\{\bar{Q}\left[\varphi\left[p_{L H}-c_{L}\right]+[1-\varphi]\left[p_{H H}-c_{H}\right]\right]+\left[\bar{c}^{n}-c_{H}^{n}\right] Q^{n}\right\} \\
& \geq\left[\varphi_{0}^{n}+\Delta^{n}\right]\left\{\bar{Q}\left[\varphi_{0}\left[p_{L L}-c_{L}\right]+\left[1-\varphi_{0}\right]\left[p_{H L}-c_{H}\right]\right]+\left[\bar{c}^{n}-c_{L}^{n}\right] Q^{n}\right\} \\
& +\left[1-\varphi_{0}^{n}-\Delta^{n}\right]\left\{\bar{Q}\left[\varphi_{0}\left[p_{L H}-c_{L}\right]+\left[1-\varphi_{0}\right]\left[p_{H H}-c_{H}\right]\right]+\left[\bar{c}^{n}-c_{H}^{n}\right] Q^{n}\right\} ; \text { and } \\
& Q^{n} \leq \bar{Q}^{n},
\end{aligned}
$$

where $\varphi=\varphi_{0}+\Delta^{c}$ and $\varphi_{n}=\varphi_{0}^{n}$.

The objective function in $[E C]$, expression (2.1), reflects the regulator's desire to maximize expected consumers' surplus in the core market. Constraints (2.2) ensure that the regulated firm receives non-negative profit for all possible cost realizations. Constraints (2.3) rule out cost padding by ensuring that when it realizes low marginal cost $\left(c_{L}\right)$ in the non-core market, the firm prefers to reveal this low cost to the regulator rather than inflate its marginal cost (to $c_{H}$, at personal cost $\left.\delta\left[c_{H}^{n}-c_{L}^{n}\right] Q^{n}\right)$. The regulator always prefers to prevent cost padding because, with $\delta \in(0,1)$, the consumers' surplus gained by doing so exceeds the requisite compensation for the firm. Inequality (2.4) precludes effort diversion by ensuring that the firm anticipates greater expected profit when it devotes its cost-reducing effort to the core market than when it devotes this effort to the non-core market. As expression (2.6) indicates, the probability of low marginal cost is $\varphi_{0}+\Delta^{c}$ in the core market and $\varphi_{0}^{n}$ in the non-core market when effort diversion is deterred. Inequality (2.5) reflects the upper bound on consumer demand in the non-core market.

The solution to $[E C]$ characterizes the optimal regulatory policy when effort diversion is deterred. Conceivably, consumers' surplus in the core market could be higher when diversification and effort diversion are permitted. The optimal regulatory policy when effort diversion is induced 
is characterized by the solution to problem $[E N]$. Problem $[E N]$ is given by expression $(2.1)-(2.3)$ and (2.5), where $\varphi=\varphi_{0}$ and $\varphi^{n}=\varphi_{0}+\Delta^{n} \cdot{ }^{19}$

The solutions to problems $[E C]$ and $[E N]$ are characterized in section 4, after some benchmark solutions are described in section 3.

\section{Benchmark Outcomes.}

First consider the ideal outcome, which is the outcome the regulator would implement if he could simply prohibit cost padding and dictate where the firm must deliver its cost-reducing effort.

Lemma 1. In the ideal outcome: (i) full diversification $\left(Q^{n}=\bar{Q}^{n}\right)$ is always authorized; (ii) the regulated firm makes exactly zero profit; and (iii) the firm devotes its cost-reducing effort to the core market if and only if:

$$
\Delta^{c}\left[c_{H}-c_{L}\right] \bar{Q} \geq \Delta^{n}\left[c_{H}^{n}-c_{L}^{n}\right] \bar{Q}^{n} .
$$

Full diversification is authorized in the ideal outcome because the regulated firm is the least-cost supplier in the non-core market. The profit that the firm generates in the non-core market $\left(\left[\bar{c}^{n}-c_{j}{ }^{n}\right] \bar{Q}^{n}\right)$ is employed to exactly offset the loss it incurs in the core market. This loss stems from prices that are set below cost to secure greater surplus for consumers. In the ideal outcome, cost-reducing effort is directed to the market where it generates the greatest increase in expected surplus. This increase is greatest in the market where the product of the increased probability of realizing low marginal cost and the reduction in total production costs when the low cost is realized is greatest, as inequality (3.1) reveals.

Now consider the outcome the regulator would implement if he could observe the firm's

19. It is readily shown that the constraint corresponding to (2.4) which ensures that the firm prefers to devote its cost-reducing effort to the non-core market is satisfied at the solution to $[E N]$. 
realized costs in the non-core market (so cost padding is not possible), but could not dictate the firm's allocation of cost-reducing effort. Call this outcome the no-cost-padding outcome.

Lemma 2. The no-cost-padding outcome is precisely the ideal outcome.

When cost padding is not possible, the regulator can set prices in the core market to ensure that the firm's overall profit is exactly zero for all cost realizations. Consequently, the firm's financial returns do not vary according to where it directs its cost-reducing effort. Therefore, the firm is willing to devote its effort to the market in which it generates the greatest increase in expected surplus, thereby ensuring the ideal outcome. ${ }^{20}$

Now consider the outcome that would prevail if the regulator could dictate the firm's allocation of its cost-reducing effort but could not similarly dictate that the firm refrain from cost padding. Call the outcome in this setting the no-effort-diversion outcome.

Lemma 3. In the no-effort-diversion outcome: (i) full diversification is always authorized; (ii) the regulated firm earns zero profit when high costs are realized in the non-core market and a profit of $[1-\delta]\left[c_{H}^{n}-c_{L}^{n}\right] \bar{Q}^{n}$ when low costs are realized in the non-core market; and (iii) the firm's cost-reducing effort is directed to the core market if and only if:

$$
\Delta^{c}\left[c_{H}-c_{L}\right] \bar{Q} \geq \delta \Delta^{n}\left[c_{H}^{n}-c_{L}^{n}\right] \bar{Q}^{n}
$$

Full diversification is authorized in the no-effort-diversion outcome because the regulator is able to secure for core customers some, but not all, of the constant level of profit that the regulated firm

20. When indifferent among actions, the firm is assumed to undertake the action preferred by the regulator. If a strict preference were required to ensure that the firm acts in the regulator's interest, the regulator could implement this strict preference at arbitrarily small cost. 
generates on each unit of output it produces in the non-core market. To induce the firm to refrain from cost padding when low costs $\left(c_{L}^{n}\right)$ are realized in the non-core market, the regulator must grant the firm the rent it could secure through cost padding $\left([1-\delta]\left[c_{H}^{n}-c_{L}^{n}\right] \bar{Q}^{n}\right)$. Because he cannot capture the full increment in surplus that results when the regulated firm realizes low production costs in the non-core market, the regulator is more likely to allocate the firm's cost-reducing effort to the core market than he is in the ideal outcome, as a comparison of inequalities (3.1) and (3.2) reveals.

To minimize prices in the core market, the regulator provides rent to the firm only when required to do so to prevent cost padding, i.e., only when low costs $\left(c_{L}{ }^{n}\right)$ are realized in the non-core market. The firm receives no incremental reward for realizing low costs in the core market in the noeffort-diversion outcome. Consequently, if the firm were free to allocate its cost-reducing effort, it would allocate the effort to the non-core market (where it secures incremental profit $[1-\delta]\left[c_{H}^{n}-c_{L}^{n}\right] \bar{Q}^{n}$ when low costs are realized). Therefore, the regulator must provide added incentive for the firm to allocate its effort to the core market when this is the desired allocation and when the firm, not the regulator, selects the allocation.

Lemmas 1 - 3 provide two important observations. First, the fundamental impediment facing the regulator is his limited knowledge of the non-core market. If the regulator could identify the realized capabilities of the regulated firm in the non-core market, he could ensure the ideal outcome even though he is unable to observe or dictate the allocation of the firm's cost-reducing effort. Second, full diversification will always be implemented when the regulator faces only one limitation: either a limited ability to prevent cost padding or an inability to preclude effort diversion. Thus, if full diversification is precluded in the present setting, the preclusion will result from a combination 
of the two limitations.

\section{Diversification Policies.}

There are three distinct policies the regulator might pursue: (1) prohibit diversification; (2) authorize full diversification and permit effort diversion; or (3) authorize full diversification and preclude effort diversion. ${ }^{21}$ The purpose of this section is to describe how the regulator optimally pursues each of these policies. Section 5 provides a ranking of the policies.

When the regulator prohibits diversification, he avoids all concerns about effort diversion and cost padding. Consequently, the optimal regulatory policy is straightforward in this case. The coremarket price is set equal to realized marginal cost. This pricing policy ensures that the firm earns zero profit and allocates its cost-reducing effort to the core market, as indicated in Lemma 4.

Lemma 4. When the regulator prohibits diversification, he will set price equal to realized marginal cost in the core market (i.e., $p_{i_{\bullet}}=c_{i}$ ), thereby ensuring zero profit for the regulated firm while precluding effort diversion.

Now consider the optimal manner in which to ensure (full) diversification and effort diversion. In this case, the regulator reduces prices in the core market to eliminate the firm's overall profit when high costs $\left(c_{H}^{n}\right)$ are realized in the non-core market. The regulator cedes the minimum rent $\left([1-\delta]\left[c_{H}^{n}-c_{L}^{n}\right] \bar{Q}^{n}\right)$ required to prevent cost padding when low costs $\left(c_{L}^{n}\right)$ are realized in the non-core market, as indicated in Lemma 5 . The statement of Lemma 5 refers to $\pi_{i j}$, which is the overall profit of the regulated firm when marginal costs $c_{i}$ and $c_{j}{ }^{n}$ are realized in the core market

21. In principle, the regulator might also authorize partial diversification $\left(Q^{n} \in\left(0, \bar{Q}^{n}\right)\right)$. However, the linearity of the model ensures that the regulator never strictly prefers partial diversification to both full diversification and no diversification. 
and the non-core market, respectively (for $i, j=L, H$ ).

Lemma 5. When the regulator authorizes full diversification and admits effort diversion: (i) $p_{i H}=$ $c_{i}-g$ and $p_{i L}=c_{i}-g-\delta \hat{g} ;$ and so (ii) $0=\pi_{i H}<\pi_{i L}=[1-\delta]\left[c_{H}^{n}-c_{L}^{n}\right] \bar{Q}^{n}$ for $i=L, H$, where $g \equiv\left[\bar{c}^{n}-c_{H}^{n}\right] \bar{Q}^{n} / \bar{Q}$ and $\hat{g} \equiv\left[c_{H}^{n}-c_{L}^{n}\right] \bar{Q}^{n} / \bar{Q}$.

Notice from property (ii) of Lemma 5 that the firm's profit increases when it realizes lower costs in the non-core market, but not when it realizes lower costs in the core market. Consequently, the firm will devote its cost-reducing effort to the non-core market.

To induce the firm to apply its cost-reducing effort in the core market when diversification is authorized, the regulator must increase the firm's incremental reward for realizing low costs in the core market. As Lemma 6 reveals, the minimum increase in this incremental reward required to preclude effort diversion is $I^{c} \equiv[1-\delta] \frac{\Delta^{n}}{\Delta^{c}}\left[c_{H}^{n}-c_{L}^{n}\right] \bar{Q}^{n}$. This minimum incremental reward is simply the product of: (1) the rent the firm must be afforded to prevent cost padding in the non-core market; and (2) the relative impact ratio, $\frac{\Delta^{n}}{\Delta^{c}}$. The relative impact ratio measures the increase in the probability of low costs that results from applying the firm's cost-reducing effort in the non-core market to the corresponding increase when the effort is applied in the core market. The larger is the relative impact ratio, the greater is the profit the firm anticipates from devoting its cost-reducing effort to its non-core operations, and thus the greater is the incremental reward for realizing low costs in the core market the firm must be promised in order to preclude effort diversion.

Lemma 6. When the regulator authorizes full diversification and precludes effort diversion: (i)

$$
\begin{aligned}
& p_{H H}=c_{H}-g ; \quad p_{L H}=c_{L}-g+I^{c} / \bar{Q} ; \quad p_{H L}=c_{H}-g-\delta \hat{g} ; \quad p_{L L}=c_{L}-g-\delta \hat{g}+ \\
& I^{c} / \bar{Q} ; \text { and (ii) } \pi_{H H}=0 ; \pi_{L H}=I^{c} ; \pi_{H L}=[1-\delta]\left[c_{H}^{n}-c_{L}^{n}\right] \bar{Q}^{n} ; \pi_{L L}=\pi_{H L}+I^{c} .
\end{aligned}
$$


Figure 1 depicts the price-cost margins that are optimally implemented under the three policies described in Lemmas 4 - 6. Notice that diversification guarantees lower prices in the core market when realized costs are high there, and it may secure lower core-market prices more generally. However, when diversification is authorized, the firm must be afforded a higher price-cost margin in the core market when costs are low there in order to preclude effort diversion. The associated rent for the firm may outweigh the increase in total expected surplus that arises when diversification is permitted. Consequently, when it is important to prevent effort diversion, the regulator may prohibit diversification, as the analysis in section 5 reveals.

\section{Optimal Diversification Policy.}

The regulator will optimally implement the policy that provides the highest level of expected consumers' surplus in the core market. Denote by $W^{N D}, W^{D E N}$, and $W^{D E C}$, respectively, this level of surplus when diversification is prohibited, when diversification and effort diversion are permitted, and when diversification is permitted but effort diversion is precluded. Proposition 1 provides explicit expressions for these welfare measures.

Proposition 1. The level of expected consumers' surplus secured under the three policies described

in Lemmas 4, 5, and 6, respectively, are:

$$
\begin{aligned}
& W^{N D}=W^{*}+\Delta^{c}\left[c_{H}-c_{L}\right] \bar{Q}, \text { where } W^{*} \equiv \bar{Q}\left[\bar{p}-\varphi_{0} c_{L}-\left[1-\varphi_{0}\right] c_{H}\right] ; \\
& W^{D E N}=W^{*}+\bar{Q}^{n}\left[\bar{c}^{n}-c_{H}^{n}+\delta\left[\varphi_{0}^{n}+\Delta^{n}\right]\left[c_{H}^{n}-c_{L}^{n}\right]\right] ; \text { and } \\
& W^{D E C}=W^{N D}+\bar{Q}^{n}\left[\bar{c}^{n}-c_{H}^{n}+\delta \varphi_{n}^{0}\left[c_{H}^{n}-c_{L}^{n}\right]\right]-\left[\varphi_{0}+\Delta^{c}\right] I^{c}, \\
& \text { where } I^{c} \equiv[1-\delta] \frac{\Delta^{n}}{\Delta^{c}}\left[c_{H}^{n}-c_{L}^{n}\right] \bar{Q}^{n} .
\end{aligned}
$$


The welfare measures in Proposition 1 are readily interpreted. When diversification is prohibited, the firm devotes its cost-reducing effort to the core market. Doing so increases by $\Delta^{c}$ the probability of realizing cost savings $\left[c_{H}-c_{L}\right] \bar{Q}$. These cost savings are optimally awarded to customers in the core market in addition to the surplus generated by marginal cost pricing $\left(W^{*}\right)$, as reflected in expression (5.1). When diversification and effort diversion are admitted, the increased probability of cost savings in the core market $\left(\Delta^{c}\right)$ is not realized. Instead, consumers in the core market receive the incremental expected appropriable surplus generated in the non-core market. This appropriable surplus is the sum of: (1) the cost savings $\left(\left[\bar{c}^{n}-c_{H}^{n}\right] \bar{Q}^{n}\right)$ generated in the non-core market when the regulated firm has high costs $\left(c_{H}^{n}\right)$; and (2) the additional cost savings ( $\left.\left[c_{H}^{n}-c_{L}^{n}\right] \bar{Q}^{n}\right)$ when the firm has low costs $\left(c_{L}^{n}\right)$, discounted by the probability of low costs $\left(\varphi_{0}^{n}+\Delta^{n}\right)$ and the firm's cost of cost padding $(\delta)$, as indicated in expression (5.2).

When diversification is permitted and effort diversion is precluded, consumers in the core market once again receive the increased expected cost savings in the core market $\left(\Delta^{c}\left[c_{H}-c_{L}\right] \bar{Q}\right)$. They also receive the incremental expected appropriable surplus $\left(\bar{Q}\left[\bar{c}^{n}-c_{H}^{n}+\delta \varphi_{0}^{n}\left[c_{H}^{n}-c_{L}^{n}\right]\right)\right.$ that results from the regulated firm's operation in the non-core market. But consumers forfeit the expected rent that must be afforded the firm $\left(\left[\varphi_{0}+\Delta^{c}\right] I^{c}\right)$ to preclude effort diversion, as expression (5.3) reveals.

These considerations underlie the following three corollaries.

Corollary 1. The regulator optimally authorizes full diversification while precluding effort diversion if the equilibrium incremental expected appropriable surplus in the non-core market exceeds the expected rent required to preclude effort diversion, i.e., if 


$$
\left[\bar{c}^{n}-c_{H}^{n}+\delta \varphi_{0}^{n}\left[c_{H}^{n}-c_{L}^{n}\right]\right] \bar{Q}^{n}>\left[\varphi_{0}+\Delta^{c}\right] I^{c}
$$

Corollary 2. The regulator optimally authorizes full diversification and allows effort diversion if the equilibrium incremental expected appropriable surplus in the non-core market exceeds the incremental expected cost savings that arise in the core market when effort diversion is precluded, i.e., if

$$
\left[\bar{c}^{n}-c_{H}^{n}+\delta\left[\varphi_{0}+\Delta^{n}\right]\left[c_{H}^{n}-c_{L}^{n}\right]\right] \bar{Q}^{n}>\Delta^{c}\left[c_{H}-c_{L}\right] \bar{Q} .
$$

Corollary 3. The regulator optimally prohibits diversification if neither of the conditions cited in Corollaries 1 and 2 holds (i.e., if the inequalities in expressions (5.5) and (5.6) are both reversed).

Corollaries 1 and 2 simply state that the regulator will authorize full diversification if the resulting expected appropriable surplus generated in the non-core market exceeds either the expected rent that must be ceded to the firm to preclude effort diversion (inequality (5.5)) or the incremental expected cost savings generated in the core market when the firm employs its cost-reducing effort there (inequality (5.6)). Corollary 3 states that if the expected appropriable surplus from diversification is outweighed by each of these other quantities (which represent the cost of diversification with and without effort diversion), then diversification will be prohibited.

Corollaries 1 - 3 provide some simple sufficient conditions for diversification to be authorized and to be prohibited. To illustrate, expressions (5.4) and (5.5) reveal that diversification will be permitted whenever the regulator's ability to detect cost padding in the non-core market is sufficiently good (i.e., whenever $\delta$ is sufficiently close to 1 ). In this case, little rent must be ceded to the diversified firm to preclude effort diversion, so the benefits of diversification (with no effort 
diversion) outweigh the costs. Expression (5.6) indicates that diversification will be authorized whenever the certain (and fully appropriable) increase in non-core surplus $\left(\left[\bar{c}^{n}-c_{H}^{n}\right] \bar{Q}^{n}\right)$ that diversification secures outweighs the expected increase in core surplus $\left(\Delta^{c}\left[c_{H}-c_{L}\right] \bar{Q}\right)$ that arises when effort diversion is precluded. In contrast, Corollary 3 implies that diversification will be prohibited whenever the certain increase in non-core surplus $\left(\left[\bar{c}^{n}-c_{H}^{n}\right] \bar{Q}^{n}\right)$ that diversification provides is sufficiently small and the regulator's ability to detect cost padding in the non-core market is sufficiently poor (i.e., $\delta$ is sufficiently close to zero). In this case, the regulator can only capture for core-market customers very little of the expected surplus that diversification generates in the noncore market, and so the cost of diversification outweighs its expected benefit. ${ }^{22}$

Proposition 2 supplements these sufficient conditions for full diversification and no diversification by explaining how the likelihood that the regulator will prohibit diversification is affected by key elements of the environment.

Proposition 2. The regulator is more likely to prohibit diversification when, ceteris paribus: ${ }^{23}$ (i) cost padding is more difficult to detect (so $\delta$ is small); (ii) the certain cost reduction $\left(\bar{c}^{n}-c_{H}^{n}\right)$ that the regulated firm generates in the non-core market is small; (iii) consumer demand $\left(\bar{Q}^{n}\right)$, and thus potential surplus, in the non-core market is small; (iv) the potential increase in coremarket surplus from reducing costs $\left(\left[c_{H}-c_{L}\right] \bar{Q}\right)$ is large; (v) low costs are likely in the core

22. This conclusion suggests that when there are a variety of unregulated markets into which the regulated firm might diversify, the regulator will tend to favor diversification into those markets that promise the largest certain profit for the firm, even if they do not provide the greatest expected profit.

23. Formally, a parameter change that renders the regulator more likely to prohibit diversification is one that results in inequalities (5.5) and (5.6) both being violated, whereas one or both inequalities were satisfied before the change. 
market (so $\varphi_{0}$ is large); and (vi) low costs are unlikely in the non-core market (so $\varphi_{0}^{n}$ is small).

The first four conditions in Proposition 2 simply indicate that the regulator is more likely to prohibit diversification when the appropriable gains from diversification are small and the potential costs of diversification (in terms of reduced surplus in the core market due to effort diversion) are large. Condition (vi) has a similar interpretation. It indicates that diversification is more likely to be prohibited when the total expected increase in non-core surplus is small, because the regulated firm is unlikely to realize low production costs $\left(c_{L}^{n}\right)$. Condition (v) reports that the regulator is less prone to authorize diversification when the likelihood of having to deliver relatively high payments to the firm to preclude effort diversion is pronounced. (Recall from Lemma 6 and Figure 1 that these payments are delivered when low costs are realized in the core market.)

One might expect that the regulator would become more inclined to authorize diversification as the expected surplus that the regulated firm can secure in the non-core market increases. Proposition 3 reveals that this is not necessarily the case.

Proposition 3. The regulator may become more likely to prohibit diversification as the regulated firm becomes capable of generating greater expected surplus in the non-core market (e.g., as $\Delta^{n}$ increases or as $c_{L}^{n}$ decreases).

Proposition 3 holds because the same factors that increase the expected surplus the regulated firm generates in the non-core market can increase the cost of deterring effort diversion by the diversified firm. To illustrate, as $c_{L}^{n}$ declines, the maximum cost reduction that the regulated firm can secure in the non-core market — and thus the maximum potential gain from diversification increases. However, a decrease in $c_{L}^{n}$ also increases the rent that the regulated firm secures when it 
realizes low costs in the non-core market. Consequently, a decrease in $c_{L}^{n}$ increases the diversified firm's expected financial gain from effort diversion, which makes it more costly for the regulator to deter effort diversion by the diversified firm. Therefore, when the regulator is intent on precluding effort diversion (because, for example, $\Delta^{c}\left[c_{H}-c_{L}\right] \bar{Q}$ is large), he may find it relatively more attractive to do so by prohibiting diversification as $c_{L}^{n}$ decreases. One implication of Proposition 3 is that a regulator may optimally prohibit diversification into a market where the regulated firm is particularly likely to improve industry performance, while authorizing diversification into a market where the firm's likely impact is thought to be less pronounced.

One might also suspect that the regulator would be more likely to prohibit diversification (and thereby preclude effort diversion) as the impact of the firm's cost-reducing effort $\left(\Delta^{c}\right)$ in the core market becomes more pronounced. However, as Proposition 4 reports, this is not necessarily the case.

Proposition 4. The regulator may be more likely to authorize diversification as the potential gains from devoting cost-reducing effort to the core market increase (i.e., as $\Delta^{c}$ increases).

Although an increase in $\Delta^{c}$ increases the expected gain from precluding effort diversion, it also reduces the cost of precluding effort diversion by a diversified firm. As $\Delta^{c}$ increases, the incremental payment that must be delivered to the diversified firm when it realizes low costs in the core market in order to deter effort diversion decreases (as expression (5.4) reveals). Since effort diversion by a diversified firm can be precluded at lower cost as $\Delta^{c}$ increases, the regulator may be more likely to authorize diversification as $\Delta^{c}$ increases. As the proof of Proposition 4 indicates, this is particularly likely to be the case when the regulator's ability to detect cost padding by (and thereby 
limit the rent of) the diversified firm is relatively pronounced.

Propositions 2 - 4 reveal that although certain prescriptions regarding optimal diversification policy are intuitive, others are less straightforward. Therefore, the optimal design of diversification policy can involve significant subtleties even in the relatively simple setting analyzed here. Additional considerations that arise in more complex settings are discussed in the concluding section.

\section{Conclusions.}

Diversification by a regulated enterprise can secure additional surplus for the firm's core customers. However, diversification can also tempt the firm to focus its creative energies outside of its core market, thereby disadvantaging core customers. Because of these countervailing effects, diversification may or may not be in the best interest of core customers. This research has employed a simple, stylized model to identify both the conditions under which diversification into an unregulated market is optimally authorized or prohibited, and the core-market pricing policy that accompanies the diversification decision.

The foregoing analysis suggests that a regulator might undertake the following six steps when determining whether to authorize diversification into an unregulated, non-core market. First, assess the regulated firm's ability to generate profit in the non-core market. Only if expected profit is substantial can customers in the firm's core market anticipate pronounced benefits from diversification. Second, distinguish the portion of expected profit that is virtually certain to arise from the portion that is more speculative. Third, if the speculative component of non-core profit is large, assess the regulator's ability to identify and capture realized profit for core market customers. In particular, consider the ability and incentive of the diversified enterprise to understate realized 
revenues, to exaggerate realized costs, or to otherwise prevent the delivery of realized profit to coremarket customers. If this ability and incentive are pronounced and cannot be mitigated, then coremarket customers are unlikely to benefit substantially from realized non-core profit that was initially deemed to be possible, but not certain. Fourth, assess the likelihood and potential consequences of effort diversion from the core market under the prevailing regulatory regime. If the regulated firm can easily and clandestinely re-direct very valuable expertise and key resources from core to noncore activities, then the costs of diversification may be large. Fifth, if effort diversion is a serious concern, identify practical policies that will limit the incentives of a diversified regulated firm to allocate excessive attention to non-core activities. Incentive regulation, whereby the firm is rewarded financially for delivering superior value to core-market customers, may be an important component of such policies. Sixth, and finally, assess whether the expected appropriable surplus from activities in the non-core market outweigh the expected losses either from unavoidable effort diversion or from the changes in regulatory policy designed to limit effort diversion. Only if the expected appropriable surplus outweighs both of these potential costs will diversification be in the interest of core-market customers.

These six steps may provide some guidance regarding appropriate diversification policy. However, they do not provide complete answers. Each step entails numerous considerations and requires considerable information to implement. Thus, the diversification decision is an intricate and complex one. Even in the simple setting analyzed here, counterintuitive conclusions can arise. For instance, as Proposition 3 reveals, diversification does not necessarily become more attractive as the regulated firm's expected profit from non-core activities increases. Greater expected non-core profit can increase the incentive of the firm to divert its efforts from core activities to non-core activities, 
thereby rendering diversification more costly to core market customers.

While the foregoing analysis documents some of the subtleties in the design of diversification policy, it also provides some general generic principles, including the following three. First, the merits of diversification into non-core markets will vary with the nature of regulatory policy in the core market. The stronger is the regulated firm's financial incentive to deliver high value to core market customers, the less pronounced will be its incentive to divert crucial resources from core to non-core activities. Second, the merits of diversification designed to secure profit for core market customers will depend upon the regulator's ability to limit effort diversion and cost padding. Strict accounting standards, separate subsidiary requirements, and restrictions on joint operations and the movement of key personnel with the diversified enterprise can be beneficial in this regard. Third, even if the sole purpose of diversification into non-core markets is to generate profit to share with core market customers, the magnitude of expected profit from non-core operations is not the only relevant consideration-and perhaps not even the main consideration-when assessing the merits of diversification. Even if expected profit is large, appropriable profit may not be if cost padding is difficult to preclude. Furthermore, the expected gains from appropriable profit may be small relative to the expected losses from effort diversion that can arise when diversification is permitted.

As noted above, these conclusions were derived formally in a simple, stylized model. Although the central effects analyzed here persist more generally, ${ }^{24}$ additional considerations can arise. Four such considerations are noted in closing. First, the optimal regulatory policy may involve partial

24. Notice, for example, that the central conclusions drawn here also apply to the setting where, perhaps for legal reasons or because of inherent monitoring difficulties, the regulator cannot base core-market prices on realized costs in non-core markets. The optimal policy toward diversification in this case is as characterized above for the limiting case where $\delta=0$, as is evident from property (i) in Lemmas 5 and 6. 
diversification in the presence of non-linear costs, more elastic demand functions, and/or alternative forms of competition in non-core markets. In the present linear model, the incremental benefits and costs of expansion into the non-core market do not vary with the scale of the expansion. More generally, the incremental benefits of expansion may decline and the corresponding costs may increase with the scale of expansion. Under such circumstances, the regulator may optimally authorize only limited operations in non-core markets. ${ }^{25}$ Second, the optimal diversification policy may induce a less extreme division of effort across markets. A regulated firm will typically be able to devote a fraction of its innovative efforts to many different activities simultaneously. And when there are diminishing returns to effort on each activity, the firm will often prefer to spread its effort across diverse activities. In such a setting, diversification policy will optimally be designed to influence the firm's richer choice of effort allocation. ${ }^{26} \quad$ Notice that if there are non-trivial fixed costs associated with diverting effort from core to non-core activities, a regulator may optimally allow only limited diversification in order to render effort diversion unduly expensive for the firm.

Third, diversification may promise greater benefits when the regulator is endowed with an expanded set of policy instruments in the core market. For example, if the regulator can reduce the diversified firm's profit below zero when its performance in the core market declines, the regulator need not promise (as much) rent to the firm in its core market activities in order to limit effort

25. Notice that the regulated firm's participation in non-core markets will typically affect the equilibrium price in those markets. The resulting effect on consumers' surplus in the non-core markets would warrant consideration in any complete analysis of the benefits and costs of diversification.

26. As a referee has suggested, the models of Holmstrom and Milgrom $(1987,1991)$ might readily be adapted to introduce a richer effort allocation choice for the firm. 
diversion. ${ }^{27}$ In addition, by linking expanded diversification opportunities to core market performance under the prevailing limited scale of diversification, the regulator may be able to limit the firm's incentives for effort diversion.

Fourth, and finally, the properties of optimal diversification policies will generally differ in the presence of asymmetric information. If the firm has superior knowledge about likely profit or opportunities for cost padding in the non-core market, for example, the regulator may optimally allow the firm to select one diversification/compensation plan from a carefully designed menu of such plans. By doing so, the regulator may be able to induce the firm to employ its superior knowledge in the best interest of core market customers.

\section{Acknowlegements}

27. Notice that the qualitative conclusions drawn above would be altered if the regulated firm could be forced to pay in advance for the right to diversify into unregulated markets. In this case, the regulator could secure for core customers as an initial lump-sum payment the entire profit that the firm expects to earn in its non-core operations. But large initial payments of this form are not common in practice, perhaps due to asymmetric information about expected profit, to capital constraints, and/or to concerns about the regulator's propensity to change the terms of the announced policy once the firm has fulfilled its obligations to core customers in advance. 
I am grateful to Tim Brennan, John Mayo, Gregory Sidak, Dennis Weisman, and two anonymous referees for helpful comments and observations. 


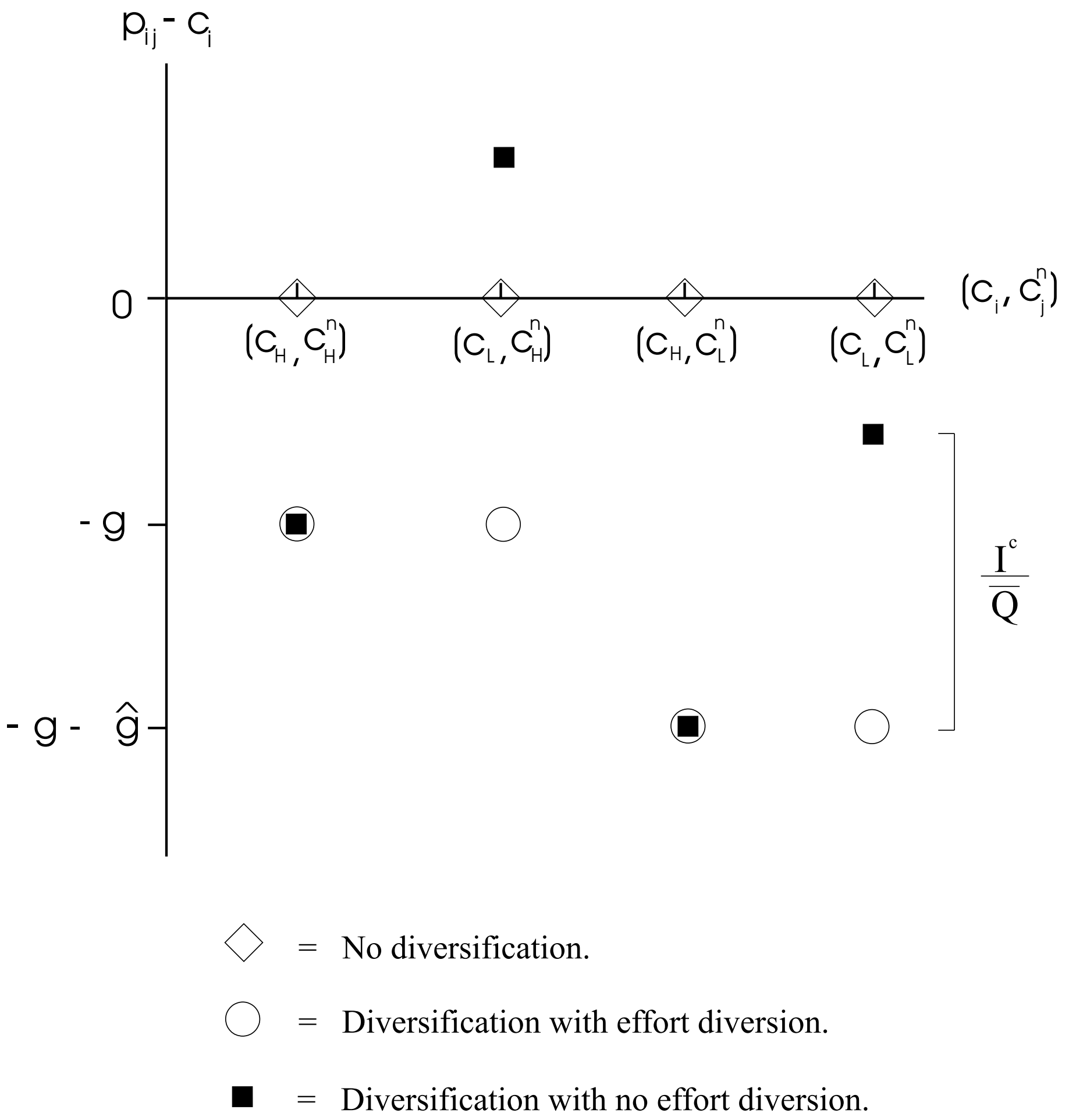

Figure 1. Optimal Price-Cost Margins. 


\section{APPENDIX}

The proofs of Lemmas 1 - 4 follow directly from the explanations provided in the text, and so are omitted. The proof of Lemma 5 is also omitted because it is analogous to the proof of Lemma 6.

\section{Proof of Lemma 6.}

Let $\lambda_{i j}, \gamma_{i}, \eta$, and $\eta^{n}$ denote the Lagrange multipliers associated with constraints (2.2), (2.3), (2.4), and (2.5), respectively. Then, after some simplification, the necessary conditions for a solution to $[E C]$ are readily shown to include:

$$
\begin{gathered}
-\varphi_{0}^{n}\left[\varphi_{0}+\Delta^{c}\right]+\lambda_{L L}+\gamma_{L}+\eta\left[\varphi_{0}^{n} \Delta^{c}-\varphi_{0} \Delta^{n}\right]=0 \\
-\left[1-\varphi_{0}^{n}\right]\left[\varphi_{0}+\Delta^{c}\right]+\lambda_{L H}-\gamma_{L}+\eta\left[\left[1-\varphi_{0}^{n}\right] \Delta^{c}+\varphi_{0} \Delta^{n}\right]=0 \\
-\varphi_{0}^{n}\left[1-\varphi_{0}-\Delta^{c}\right]+\lambda_{H L}+\gamma_{H}-\eta\left[\varphi_{0}^{n} \Delta^{c}+\left[1-\varphi_{0}\right] \Delta^{n}\right]=0 ; \\
-\left[1-\varphi_{0}^{n}\right]\left[1-\varphi_{0}-\Delta^{c}\right]+\lambda_{H H}-\gamma_{H}-\eta\left[\left[1-\varphi_{0}^{n}\right] \Delta^{c}-\left[1-\varphi_{0}\right] \Delta^{n}\right]=0 ; \\
{\left[\lambda_{H H}+\lambda_{L H}\right]\left[\bar{c}^{n}-c_{H}^{n}\right]+\left[\lambda_{H L}+\lambda_{L L}\right]\left[\bar{c}^{n}-c_{L}^{n}\right]} \\
+\left[c_{H}^{n}-c_{L}^{n}\right]\left[\delta\left[\gamma_{L}+\gamma_{H}\right]-\eta \Delta^{n}\right]-\eta^{n} \leq 0
\end{gathered}
$$

Summing (A1) and (A2), and then (A3) and (A4), provides:

$$
\begin{aligned}
& \lambda_{L L}+\lambda_{L H}+\eta \Delta^{c}=\varphi_{0}+\Delta^{c}, \text { and } \\
& \lambda_{H L}+\lambda_{H H}-\eta \Delta^{c}=1-\varphi_{0}-\Delta^{c} .
\end{aligned}
$$

Summing (A6) and (A7) provides:

$$
\lambda_{H H}+\lambda_{H L}+\lambda_{L H}+\lambda_{L L}=1
$$

To focus on the case of primary interest where diversification is not prohibited altogether, suppose $Q^{n}>0$, so that (A5) holds as an equality. In this case:

$$
\lambda_{L L}=0 \text { and/or } \quad \lambda_{L H}=0 ; \text { and }
$$




$$
\lambda_{H L}=0 \text { and/or } \lambda_{H H}=0 .
$$

To prove that (A9) is true, suppose that $\lambda_{L L}>0$ and $\lambda_{L H}>0$. Then the complementary slackness conditions associated with constraints (2.2) imply:

$$
\left[p_{L L}-c_{L}\right] \bar{Q}+Q^{n}\left[\bar{c}^{n}-c_{L}^{n}\right]=0=\left[p_{L H}-c_{L}\right] \bar{Q}+Q^{n}\left[\bar{c}^{n}-c_{H}^{n}\right] .
$$

(A11) implies:

$$
\left[p_{L L}-p_{L H}\right] \bar{Q}+Q^{n}\left[c_{H}^{n}-c_{L}^{n}\right]=0 .
$$

Since $Q^{n}>0$ and $\delta<1$, (A12) implies:

$$
\left[p_{L L}-p_{L H}\right] \bar{Q}+\delta Q^{n}\left[c_{H}^{n}-c_{L}^{n}\right]<0 .
$$

But it is readily verified that inequality (2.3) cannot hold for $i=L$ if (A13) holds. Hence, (A9) must hold, by contradiction. The proof that (A10) holds is analogous.

If $\eta=0$, then $\lambda_{H H}>0$ and $\lambda_{L H}>0$ from(A4) and (A2), respectively. Therefore, $\lambda_{H L}=0$ and $\lambda_{L L}=0$ from (A10) and (A9), respectively. Consequently, $\gamma_{H}>0$ and $\gamma_{L}>0$ from(A3) and (A1), respectively. When $\gamma_{L}>0$ and $\gamma_{H}>0,(2.3)$ implies:

$$
p_{L L}+p_{H H}-p_{H L}-p_{L H}=0 .
$$

Arguments analogous to those employed to prove that (A10) holds reveal that since $\lambda_{H H}>0$ :

$$
\left[p_{H L}-c_{H}\right] \bar{Q}+Q^{n}\left[\bar{c}^{n}-c_{L}^{n}\right]>0 .
$$

Also, since $\lambda_{L H}>0$ :

$$
\left[p_{L H}-c_{L}\right] \bar{Q}+Q^{n}\left[\bar{c}^{n}-c_{H}^{n}\right]=0 .
$$

Furthermore, since $\lambda_{H H}>0$ and $\lambda_{L H}>0$, it follows from (2.2) that:

$$
p_{L H}-c_{L}=p_{H H}-c_{H} .
$$

Subtracting (A15) from (A16) and then substituting from (A17) provides:

$$
-\bar{Q}\left[p_{H L}-p_{H H}\right]-Q^{n}\left[c_{H}^{n}-c_{L}^{n}\right]<0 .
$$

But it is readily verified that when (A14) and (A17) hold, (2.4) requires: 


$$
\begin{gathered}
-\mathrm{A} 3- \\
\Delta^{n}\left[-\bar{Q}\left[p_{H L}-p_{H H}\right]-Q^{n}\left[c_{H}^{n}-c_{L}^{n}\right]\right] \geq 0 .
\end{gathered}
$$

Since (A18) implies that (A19) cannot hold, it follows that $\eta>0$.

(A7) implies that $\lambda_{H L}>0$ and/or $\lambda_{H H}>0$. Arguments analogous to those employed to prove that (A10) holds reveal that (2.3) cannot hold for $i=H$ if $\lambda_{H L}>0$. Hence:

$$
\lambda_{H L}=0 \text { and } \lambda_{H H}>0 .
$$

A corresponding argument reveals that if $\lambda_{L L}>0$, then (2.3) is violated for $i=L$. Consequently, $\lambda_{L L}=0$.

Since $\lambda_{H L}=0,(\mathrm{~A} 3)$ implies:

$$
\gamma_{H}=\eta\left[\varphi_{0}^{n} \Delta^{c}+\left[1-\varphi_{0}\right] \Delta^{n}\right]+\varphi_{0}^{n}\left[1-\varphi_{0}-\Delta^{c}\right]>0 .
$$

Also, since $\lambda_{L L}=\lambda_{H L}=0$, (A1) and (A3) imply:

$$
\gamma_{L}+\gamma_{H}=\eta \Delta^{n}+\varphi_{0}^{n} .
$$

Subtracting (A21) from (A22) provides:

$$
\gamma_{L}=\varphi_{0}^{n}\left[\varphi_{0}+\Delta^{c}\right]+\eta\left[\varphi_{0} \Delta^{n}-\varphi_{0}^{n} \Delta^{c}\right] .
$$

And substituting (A21) into (A4) provides:

$$
\lambda_{H H}=1-\varphi_{0}-\Delta^{c}+\eta \Delta^{c}>0 .
$$

Suppose $\gamma_{L}=0$. Then since $\lambda_{L L}=0$, (A1) implies:

$$
\eta=\frac{\varphi_{0}^{n}\left[\varphi_{0}+\Delta^{c}\right]}{\varphi_{0}^{n} \Delta^{c}-\varphi_{0} \Delta^{n}} .
$$

Since (A6) implies $\eta \leq\left[\varphi_{0}+\Delta^{c}\right] / \Delta^{c}$, (A25) implies $\varphi_{0}^{n} \Delta^{c} \leq \varphi_{0}^{n} \Delta^{c}-\varphi_{0} \Delta^{n}$. Since this inequality cannot hold, $\gamma_{L}>0$.

Since $\gamma_{L}>0$ and $\gamma_{H}>0$, it follows from (2.3) that (A14) holds. Also, since $\eta>0,(2.4)$ and (A14) imply: 


$$
\bar{Q}\left[\Delta^{c}\left[p_{L H}-c_{L}-\left(p_{H H}-c_{H}\right)\right]-\Delta^{n}\left[p_{H L}-p_{H H}\right]\right]-\Delta^{n} Q^{n}\left[c_{H}^{n}-c_{L}^{n}\right]=0 .
$$

If $\lambda_{L H}>0$, then since $\lambda_{H H}>0$, (A17) holds, and so (A26) implies:

$$
\Delta^{n}\left[\bar{Q}\left[p_{H H}-p_{H L}\right]-Q^{n}\left[c_{H}^{n}-c_{L}^{n}\right]\right]=0 .
$$

Since $\gamma_{H}>0$, it follows from (2.3) for $i=H$ that:

$$
\bar{Q}\left[p_{H H}-p_{H L}\right]=\delta Q^{n}\left[c_{H}^{n}-c_{L}^{n}\right] .
$$

Substituting (A28) into (A27) provides $[1-\delta]\left[c_{H}^{n}-c_{L}^{n}\right]=0$, which is a contradiction. Therefore, $\lambda_{L H}=0$.

In summary:

$$
\lambda_{L L}=\lambda_{L H}=\lambda_{H L}=0 .
$$

Therefore, from (A8):

$$
\lambda_{H H}=1
$$

(A30) and (A24) imply:

$$
\eta=\left[\varphi_{0}+\Delta^{c}\right] / \Delta^{c}
$$

(A31) and (A23) imply:

$$
\gamma_{L}=\varphi_{0}\left[\varphi_{0}+\Delta^{c}\right] \Delta^{n} / \Delta^{c}
$$

(A32), (A31), and (A22) imply:

$$
\gamma_{H}=\varphi_{0}^{n}+\left[1-\varphi_{0}\right]\left[\varphi_{0}+\Delta^{c}\right] \Delta^{n} / \Delta^{c} .
$$

Substituting (A29) - (A33) into (A5) provides:

$$
\bar{c}^{n}-c_{H}^{n}-\left[c_{H}^{n}-c_{L}^{n}\right]\left[\left[\varphi_{0}+\Delta^{c}\right][1-\delta] \Delta^{n} / \Delta^{c}-\delta \varphi_{0}^{n}\right]-\eta^{n} \leq 0 .
$$

(A34) implies that $Q^{n}=\bar{Q}^{n}$ if:

$$
\bar{c}^{n}-c_{H}^{n}>\left[c_{H}^{n}-c_{L}^{n}\right]\left[\left[\varphi_{0}+\Delta^{c}\right][1-\delta] \Delta^{n} / \Delta^{c}-\delta \varphi_{0}^{n}\right],
$$

and $Q^{n}=0$ if the inequality in (A35) is reversed.

Continuing for the case where (A35) holds, (A30) and (2.2) imply: 


$$
p_{H H}=c_{H}-g \text {, where } g \equiv \frac{\bar{Q}^{n}}{\bar{Q}}\left[\bar{c}^{n}-c_{H}^{n}\right] \text {. }
$$

Similarly, (A33), (2.3), and (A36) imply:

$$
p_{H L}=c_{H}-g-\delta \hat{g} \text {, where } \hat{g} \equiv \frac{\bar{Q}^{n}}{\bar{Q}}\left[c_{H}^{n}-c_{L}^{n}\right] \text {. }
$$

Similarly, since $\gamma_{L}>0$ and $\eta>0,(2.3)$ and (2.4), along with (A36) and (A37), imply:

$$
p_{L H}=c_{L}-g+I^{c} / \bar{Q} \quad \text { and } \quad p_{L L}=c_{L}-g-\delta \hat{g}+I^{c} / \bar{Q} \text {, }
$$

where $I^{c} \equiv \bar{Q}^{n}[1-\delta]\left[c_{H}^{n}-c_{L}^{n}\right] \Delta^{n} / \Delta^{c}$. (A36) - (A38) imply that the firm's profits $\left(\pi_{i j}\right)$ are as stated in the lemma.

\section{Proof of Proposition 1.}

The expression for $W^{D E C}$ in (5.3) follows immediately from substituting (A36) - (A38) into (2.1). The expression for $W^{D E N}$ in (5.2) follows in similar fashion from substituting into (2.1) the expressions for $p_{i j}$ given in property (i) of Lemma 5. The expression for $W^{N D}$ in (5.1) follows immediately from the facts that when the diversification is prohibited: (1) $\varphi=\varphi_{0}+\Delta^{c}$, since there is no effort diversion; and (2) the regulator optimally sets the price in the core market $\left(p_{i}\right)$ equal to the realized marginal cost $\left(c_{i}\right)$.

\section{Proof of Corollaries 1 - 3.}

(5.3) reveals that (5.5) is equivalent to $W^{D E C}>W^{N D}$, so that expected consumers' surplus in the core market is higher when full diversification is authorized and effort diversion is precluded than when diversification is prohibited. Similarly, (5.1) and (5.2) reveal that (5.6) is equivalent to $W^{D E N}>W^{N D}$. Also (5.1) - (5.3) reveal that if the inequalities in (5.5) and (5.6) are reversed, $W^{N D}>\max \left\{W^{D E N}, W^{D E C}\right\}$ 


\section{Proof of Proposition 2.}

Let $Z^{E C} \equiv\left[\varphi_{0}+\Delta^{c}\right][1-\delta] \frac{\Delta^{n}}{\Delta^{c}}\left[c_{H}^{n}-c_{L}^{n}\right]-\left[\bar{c}^{n}-c_{H}^{n}+\delta \varphi_{0}^{n}\left[c_{H}^{n}-c_{L}^{n}\right]\right]$, and

$$
Z^{E N} \equiv \Delta^{c}\left[c_{H}-c_{L}\right] \bar{Q}-\left[\bar{c}^{n}-c_{H}^{n}+\delta\left[\varphi_{0}^{n}+\Delta^{n}\right]\left[c_{H}^{n}-c_{L}^{n}\right]\right] \bar{Q}^{n}
$$

It follows from (5.4) - (5.6) that parameter changes that increase both $Z^{E C}$ and $Z^{E N}$ are those that will render the regulator more likely to prohibit diversification. It is apparent that $Z^{E C}$ and $Z^{E N}$ both increase (weakly, with at least one strict increase) as $\delta$ decreases, $\bar{c}^{n}-c_{H}^{n}$ decreases, $\bar{Q}^{n}$ decreases, $\left[c_{H}-c_{L}\right] \bar{Q}$ increases, $\varphi_{0}$ increases, and $\varphi_{0}^{n}$ decreases.

\section{Proof of Proposition 3.}

The statement in the proposition will be true if, for example, an increase in $\Delta^{n}$ causes inequalities (5.5) and (5.6) both to be violated, whereas at least one of the inequalities was satisfied before the postulated increase in $\Delta^{n}$. Notice from (A39) and (A40) that $Z^{E C}$ increases with $\Delta^{n}$ while $Z^{E N}$ decreases with $\Delta^{n}$. Also notice that $\operatorname{limit}_{\delta \rightarrow 0} \frac{\partial Z^{E N}}{\partial \Delta^{n}}=0$. Therefore, if $\delta$ is sufficiently small, there is a range of parameter values for which an increase in $\Delta^{n}$ will cause $Z^{E C}$ to switch from a negative to a positive number while $Z^{E N}$ remains positive.

A similar argument reveals that a decrease in $c_{L}^{n}$ can have the same impact on $Z^{E C}$ and $Z^{E N}$ as an increase in $\Delta^{n}$.

\section{Proof of Proposition 4.}

Suppose the parameters of the model are initially such that $Z^{E N}>Z^{E C}=b>0$, where $Z^{E C}$ and $Z^{E N}$ are defined in (A39) and (A40), respectively, and where $b$ is close to zero. Corollary 3 


\section{- A7 -}

implies that the regulator will optimally prohibit diversification in this case.

It is apparent from (A39) and (A40) that there is a range of parameter values for which an increase in $\Delta^{c}$ would render $Z^{E C}$ negative while $Z^{E N}$ remains positive. Thus, from Corollary 1, the increase in $\Delta^{c}$ would cause the regulator to authorize full diversification. 


\section{REFERENCES}

Averch, H. and L. Johnson, 1962, Behavior of the firm under regulatory constraint, American Economic Review 52, 1052-1069.

Baseman, K., 1981, Open entry and cross-subsidization in regulated markets, in: G.F., ed., Studies in public regulation (Cambridge, MA: MIT Press) 329-360.

Braeutigam, R., 1993, A regulatory bargain for diversified enterprises, International Journal of Industrial Organization 11, 1-20.

Braeutigam, R. and J. Panzar, 1989, Diversification incentives under "price-based" and "costbased" regulation, Rand Journal of Economics 20, 373-391.

Brennan, T., 1989, Exclusive dealing, limiting outside activity, and conflict of interest, Southern Economic Journal 56, 323-335.

Brennan, T., 1990, Cross-subsidization and cost misallocation by regulated monopolists, Journal of Regulatory Economics 2, 37-52.

Brennan, T. and K. Palmer, 1994, Comparing the costs and benefits of diversification by regulated firms, Journal of Regulatory Economics 6, 115-136.

Crew, M. and K. Crocker, 1991, Diversification and regulated monopoly, in: M. Crew, ed., Competition and the regulation of utilities (Boston, MA: Kluwer Academic Publishers) 3349 .

Economides, N., 1998, The incentive for non-price discrimination by an input monopolist, International Journal of Industrial Organization 16, 271-284.

Economides, N., 1999, Quality choice and vertical integration, International Journal of Industrial Organization 17, 903-914.

Federal Communications Commission, 1999, Annual assessment of the status of competition in markets for the delivery of video programming, CS Docket No. 99-418 (Washington, D.C).

Hinson, P., J. D. Zona, R. Schmalensee, and W. Taylor, 1998, An analysis of the welfare effects of long-distance market entry by an integrated access and long-distance provider, Journal of Regulatory Economics 13, 183-196.

Holmstrom, B. and P. Milgrom, 1991, Multi-task principal-agent analyses: incentive contracts, asset ownership, and job design, Journal of Law, Economics, and Organization 7, 24-52.

Lee, S. H. and J. Hamilton, 1999, Using market structure to regulate a vertically integrated monopolist, Journal of Regulatory Economics 15, 223-248. 
Riordan, M., 1998, Anticompetitive vertical integration by a dominant firm, American Economic Review 88, 1232-1248.

Sibley, D. and D. Weisman, 1998, Raising rivals' costs: the entry of an upstream monopolist into downstream markets, Information Economics and Policy 10, 451-470.

Sidak, J. G. and D. Spulber, 1998, Deregulatory takings and the regulatory contract (Cambridge: Cambridge University Press).

Vickers, J., 1995, Competition and regulation in vertically related markets, Review of Economic Studies 62, 1-17.

Weisman, D., 1993, Superior regulatory regimes in theory and practice, Journal of Regulatory Economics 5, 355-366.

Weisman, D., 1995, Regulation and the vertically integrated firm: the case of RBOC entry into interLATA long distance, Journal of Regulatory Economics 8, 249-266. 